\title{
Age determination and authentication of ceramics: advancements in the thermoluminescence dating laboratory in Torino (Italy)
}

\author{
Laura Guidorzi ${ }^{1,2}$, Fulvio Fantino ${ }^{3}$, Elisabetta Durisi ${ }^{1,2}$, Marco Ferrero ${ }^{2,4}$, Alessandro Re ${ }^{1,2}$, Luisa \\ Vigorelli ${ }^{1}$, Lorenzo Visca ${ }^{1,2}$, Monica Gulmini ${ }^{5}$, Giovanni Dughera², Giuseppe Giraudo ${ }^{2}$, Debora Angelici ${ }^{3}$, \\ Elisa Panero ${ }^{6}$, Alessandro Lo Giudice ${ }^{1,2}$
}

${ }^{1}$ Dipartimento di Fisica, Università di Torino, Via Pietro Giuria 1, 10125 Torino, Italy

2 INFN Sezione di Torino, Via Pietro Giuria 1, 10125 Torino, Italy

3 TecnArt S.r.l., Via Modena 58, 10153 Torino, Italy

${ }^{4}$ Università del Piemonte Orientale, Largo Guido Donegani 2, 28100 Novara, Italy

${ }^{5}$ Dipartimento di Chimica, Università di Torino, Via Pietro Giuria 5, 10125 Torino, Italy

${ }^{6}$ Musei Reali di Torino, Ministero per i Beni e le Attività Culturali, Piazzetta Reale 1, 10122 Torino, Italy

\section{ABSTRACT}

Classified as an absolute dating method, thermoluminescence (TL) is a well-established radiation-based technique for the age determination and authentication of ceramic materials. Specifically, this method allows the determination of the time elapsed since kiln firing (or later fire events) by evaluating the luminescent emission of ceramics under heating at high temperatures. This paper provides a comprehensive presentation of the TL laboratory developed over the last decade at the Physics Department of the University of Torino. The laboratory was set up in collaboration with TecnArt S.r.I. and is also currently operating within the cultural heritage network of the National Institute of Nuclear Physics (INFN-CHNet). More than 10 years of experience in the field has resulted in improvements in procedures, with the development of customised $\alpha$ - and $\beta$-irradiation systems and the optimisation of sampling approaches and chemical pre-treatment. Thanks to TecnArt S.r.l., the laboratory has been employed for dating and authenticating hundreds of archaeological sites and artworks, some of which are discussed in this work and compared, when possible, with radiocarbon dating.

Section: RESEARCH PAPER

Keywords: Thermoluminescence; dating; customised instrumentation; authentication

Citation: Laura Guidorzi, Fulvio Fantino, Elisabetta Durisi, Marco Ferrero, Alessandro Re, Luisa Vigorelli, Lorenzo Visca, Monica Gulmini, Giovanni Dughera, Giuseppe Giraudo, Debora Angelici, Elisa Panero, Alessandro Lo Giudice, Age determination and authentication of ceramics: advancements in the thermoluminescence dating laboratory in Torino (Italy), Acta IMEKO, vol. 10, no. 1, article 6, March 2021, identifier: IMEKO-ACTA-10 (2021)-01-06

Editor: Eulalia Balestrieri, University of Sannio, Italy

Received April 9, 2020; In final form September 9, 2020; Published March 2021

Copyright: This is an open-access article distributed under the terms of the Creative Commons Attribution 3.0 License, which permits unrestricted use, distribution, and reproduction in any medium, provided the original author and source are credited.

Corresponding author: Alessandro Re, e-mail: alessandro.re@unito.it

\section{INTRODUCTION}

The dating process of archaeological records can be of the utmost importance for an in-depth understanding of ancient civilisations and their development. Given the need for accurate temporal collocation, absolute dating techniques have, over time, completely complemented the archaeological relative approach [1]-[3].

Luminescence is a suitable parameter for characterising cultural heritage objects, being directly proportional to some of the intrinsic characteristics of the material. Therefore, out-ofcontext objects can also be investigated [4], [5]. The team at the University of Torino extensively applies various luminescence- based techniques, such as ionoluminescence [6]-[9] and X-ray luminescence [10], to this field, always pursuing the development of customised instrumentation tailored to archaeological and artistic samples. In 2007, a thermoluminescence (TL) dating laboratory was opened in the Physics Department, in collaboration with the National Institute of Nuclear Physics (INFN) and TecnArt Srl, a small enterprise dedicated to the scientific analysis of cultural heritage founded as a spin-off of the University of Torino. In its first decade of activity, the TL dating laboratory has provided excellent support to archaeological surveys in the nearby Piedmont area [11], [12]. The laboratory, the only one in Piedmont and one of the few providing TL dating and authentication in Italy, has been progressively expanded with new instruments and methods, which are presented in this work. 
The use of the TL process for dating purposes was introduced by Aitken et al. in the 1960s [13], [14] and is widely employed nowadays [15]-[18]. The technique allows the determination of the age of a fired clay object by measuring the natural radiation absorbed in some of its compositional minerals (e.g. quartz and feldspars) since the last firing. The luminous signal emitted by the material, when heated at a few hundred degrees Celsius in the laboratory, is proportional to the absorbed dose [19]. This means that not only the absorbed dose (palaeodose) is discovered, but also the dose rate to which the artefact has been subjected over time (annual dose), which depends on environmental conditions and varies according to the geographical area [20]-[22]. Consequently, the age can be calculated by the simple ratio between the two quantities.

Several measurements are therefore required to provide a complete dating. First, the palaeodose should be evaluated by recording the TL signal from the subsamples exposed to increasing doses of artificial irradiation from $\beta$ sources. This is known as the additive method [13]. The effective dose in grays (the only component of the palaeodose in which there are no supralinearity effects) can then be extrapolated via a linear regression of the integrated TL signal versus the corresponding value of the added artificial dose. The temperature interval to be used for integration is defined by the 'plateau test', which identifies the most thermally stable defect energy levels to be taken into account for a correct evaluation of the age [13], [14], [23]. The data needed to calculate the annual dose are then collected by measuring the artefact $\alpha$ activity (caused by the decay chain events of uranium and thorium atoms contained in the clay matrix), the environmental dose rate and the ${ }^{40} \mathrm{~K}$-isotope concentration in the material. In addition, further corrections for water absorption, the supralinearity of the TL signal and anomalous fading [13], [14], [24] are conducted. The high accuracy of all these measurements yields a final-date error that is generally lower than $15 \%$, or even $5 \%$ in more favourable cases [25].

Thermoluminescence is an invasive technique and, for a complete dating, needs the sampling of about 1-2 grams of powdered material for the preparation of subsamples via the fine grain method [26]. Clay material from archaeological objects is often contaminated by organic matter and carbonates (the latter enhanced by long exposure to highly humid burial grounds). This requires a chemical pre-treatment of the powder before the fine grain selection to eliminate these sources of spurious luminescence [13], [27], [28].

In the following section, the equipment and procedures adopted are presented; the results of two recent case studies, one for a complete dating and one for an authentication, will then be illustrated in sections 3 and 4.

\section{THE TL LABORATORY AT THE UNIVERSITY OF TORINO}

In establishing the TL laboratory in the Physics Department of the University of Torino, it was decided not to use an all-inone TL analyser so that specific components (TL reader, irradiation systems, etc.) could be adapted to the needs of analyses and samples as they arose. With the exception of the irradiation systems, which were specifically developed in our laboratory, the employed instrumentation follows the schematics and specifics illustrated in the comprehensive textbook by Aitken [13].

The main instruments currently used in the laboratory are described in the next sections. All the equipment is operated under red light, as are the sampling procedures. If necessary, sampling is followed by a chemical pre-treatment of the powder, which is outlined in section 2.7 .

\subsection{TL measurement apparatus}

The instrument setup for thermoluminescence measurement consists of a sample-holding chamber, a 9235QA Electron Tubes photomultiplier powered at $-1100 \mathrm{~V}$ by an HiVo voltage supply and the IPSES-TL2000 control unit, regulated by dedicated software. Two filters are inserted between the sample and the phototube: a KG5 filter that cuts the IR radiation and a BG25 filter that selects only photons in the blue range. The sample is placed in the chamber on a heating metal strip; a thermocouple allows the monitoring of the temperature and the control of the heating rate (generally kept constant at $5-10{ }^{\circ} \mathrm{C} / \mathrm{s}$ ). During measurements, a vacuum is generated in the chamber by a rotative pump, and nitrogen is inserted up to a pressure of 0.4 $0.6 \mathrm{bar}$ to avoid spurious luminescence and to achieve homogeneous heating for the sample. Glow curves, i.e. the intensity of the TL emission vs time, are obtained to record the TL signal every second as the temperature increases from $50^{\circ} \mathrm{C}$ to $450{ }^{\circ} \mathrm{C}$ at a fixed heating rate.

\subsection{Alpha-irradiation system}

A customised $\alpha$-irradiation system (Figure 1) was designed, realised and optimised to evaluate the $\alpha$-particle efficiency $(k)$ [29] for each analysed object. This parameter is calculated by comparing the effective doses obtained by $\alpha$ and $\beta$ irradiation on the same sample [13].

The upper part of the steel chamber contains a ${ }^{241} \mathrm{Am}$ source with nominal $4 \mathrm{MBq}$ activity and an active surface of $16 \mathrm{~cm}^{2}$. The $\alpha$ source is shielded at the top and sides; the active surface, facing down towards the sample, is protected by a $2 \mu \mathrm{m} \mathrm{Au}-\mathrm{Pd}$ layer. In addition, a steel and lead shield is situated between the source and the sample-holding wheel with an automatic shutter that opens only during measurements. Since the penetration range of an $\alpha$ particle in air is just a few centimetres, a vacuum is needed for the particle to reach the samples. With an optimal pressure of 170 mbar, the particles reach the sample with a mean energy of about $2.9 \mathrm{MeV}$, providing a dose of $2.0 \pm 0.1 \mathrm{mGy} / \mathrm{s}$. The emission rate and spectrum are measured by means of an ORTEC particle silicon detector installed in one of the sampleholder positions

\subsection{Beta-irradiation system}

For the determination of the palaeodose, $\beta$ irradiation is conducted using a ${ }^{90} \mathrm{Sr} /{ }^{90} \mathrm{Y}$ source with nominal activity of 1.48 $\mathrm{GBq}$ and a dose rate of $13.2 \pm 0.1 \mathrm{mGy} / \mathrm{s}$. The irradiation apparatus was designed and developed by the INFN (Figure 1). The new system replaced an older one, which was also custom made but bearing a source with $0.79 \mathrm{GBq}$ activity and a $7.0 \pm 0.1$ $\mathrm{mGy} / \mathrm{s}$ dose rate. As a consequence, irradiation times are now almost halved. The source is installed in a brass box, irradiating downwards and facing the sample holder. The sample holder is a wheel with four slots that is accessible through the external brass case by a hole with a screw top. Additional shielding is provided by lead plates contained in the black plexiglass case, as shown in Figure 1. The whole system is fully automated, controlled by dedicated LabView-based software, and four irradiations in a row can be set up without reopening the case. Furthermore, a quartz window with a thickness of $8 \mathrm{~mm}$ works as a shutter between the source and the sample wheel when the system is not in use. Quartz was chosen as a compromise between the $\beta$ stopping power of the material used as a shutter 


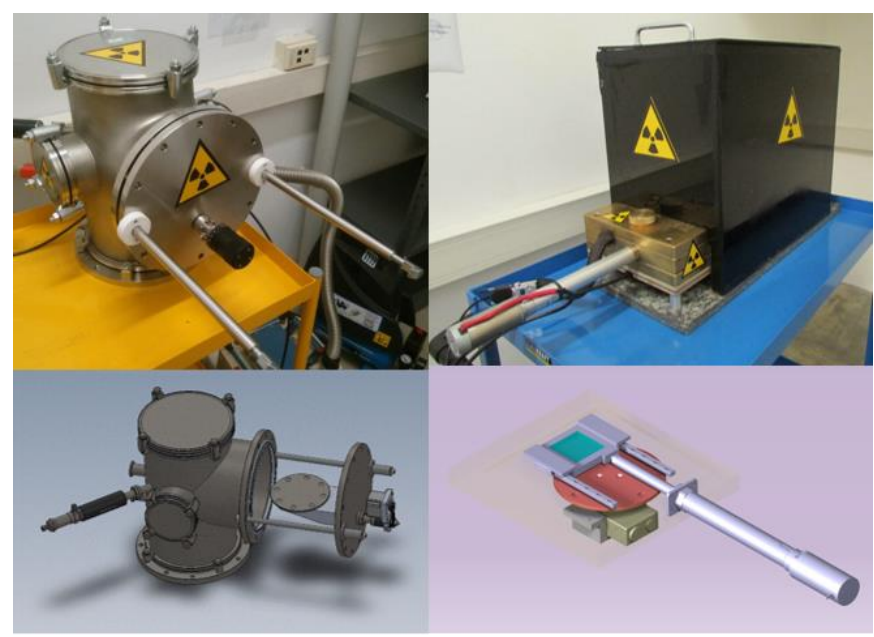

Figure 1 . On the left: $\alpha$-irradiation system with a view of the inner sampleholder wheel. On the right: $\beta$-irradiation system and a scheme of its internal structure.

and the need to minimise braking radiation production. Before the realisation, the whole apparatus was simulated using MCNP4C software [30] to calculate the irradiation dose rate and to verify the absence of radiation leakages.

In addition, the high repeatability of irradiations was tested and confirmed using (LiF:Mg,Ti) TLD-100 dosimeters.

\subsection{Alpha-activity measurements}

The uranium $(\mathrm{U})$ and thorium $(\mathrm{Th})$ atoms contained in the clay matrix of the object decay by $\alpha$-particle emission and contribute to the annual dose. The total $\alpha$ activity can be easily determined by covering a $\mathrm{ZnS}$ scintillator with a homogeneous layer of ceramic powder (at least $600 \mathrm{mg}$ ) [13]; the scintillator emits photons each time it is struck by the $\alpha$ particle, and these photons are collected by a photomultiplier powered at $-1100 \mathrm{~V}$. The generated electric signal is transferred to an Amptek MCA $8000 \mathrm{~A}$ multichannel analyser, and the real-time spectrum of the $\alpha$ counts is created. The system can also evaluate the U/Th activity ratio using the 'pairs' technique [13]. This measurement usually lasts at least $7-10$ days for suitable statistics, as the typical count rate $\dot{\alpha}$ for ceramics generally varies between 10 and 20 counts/ks.

\subsection{Environmental dose measurements}

The dose provided to the artefact by the radioisotopes present in the surrounding environment can easily be evaluated using thermoluminescent dosimeters (TLDs). These are doped crystals, typically $\mathrm{LiF}$ or $\mathrm{CaSO}_{4} / \mathrm{CaF}_{2}$, which indiscriminately accumulate energy from $\alpha, \beta$ and $\gamma$ particles, and their cumulative dose can be measured by means of thermoluminescence [31]. TLDs need to be placed in the exact spot the sample was collected from, recreating the environment in which the sample was conserved before discovery, and kept in place for a long time (approximately one month). If it is not possible to place dosimeters in situ, a good alternative is to conduct $\gamma$ spectroscopy measurements on the excavation soil [32], [33]. TL laboratory users have access to the Biomedical Physics instrumentation at the University of Torino, which is equipped with a cooled cylindric high purity germanium (HPGe) detector with a diameter of $48.2 \mathrm{~mm}$; special beakers with 'Marinelli' geometry [34] are used because of the cylindrical symmetry. The analysis supplies the activities of each radioisotope and allows the measurement of the annual dose provided by the $\mathrm{U}$ and $\mathrm{Th}$ chains as well as by ${ }^{40} \mathrm{~K}$. Finally, if it is not possible to obtain a sufficient amount of soil for the analysis, the activity can be set as equal to that of the artefact as a first approximation.

\subsection{Other measurements}

If the sample is conserved in a highly humid environment, the open porosity of the ceramic material can be filled with water that partially absorbs the ionising radiation. A correction to the annual dose is then needed, using the ratio

$$
W=\frac{w_{\text {wet }}-w_{\text {dry }}}{w_{\text {dry }}},
$$

where $w$ is the weight of the sample. For an evaluation of $W$, a small fragment of the archaeological sample is saturated with distilled water, then a Sartorius MA35 moisture analyser is used to heat it for 15 minutes up to $150{ }^{\circ} \mathrm{C}$. The weight is measured every second with an accuracy of $1 \mathrm{mg}$; when no further change in weight is detected, the $\mathrm{W}$ ratio is displayed. The moisture fraction content $F$ additionally takes into account the environmental history of the artefact and specifies the average fraction of the open porosity that has actually been filled with water. A typical value for medium-high humidity environments is $F=0.8 \pm 0.2$ [13].

The quantification of potassium $(\mathrm{K})$ content for the sample is obtained via ICP-OES analysis performed in the Chemistry Department of the University of Torino with a Perkin-Elmer Optima 2000 spectrometer. The resulting percentage by mass for $\mathrm{K}$ is then used to directly calculate the contribution to the annual dose of the radioisotope ${ }^{40} \mathrm{~K}$, up to some multiplicative constants [13], [35].

\subsection{Sample pre-treatment}

Often, the sampled powder, collected with a low-speed small drill, needs a chemical treatment for the removal of carbonates and organic matter to avoid spurious luminescence [13], [27], [28]. At first, the procedure developed by the IRAMAT-CRP2A laboratory of Bordeaux was employed, using three different reagents: hydrochloric acid $(\mathrm{HCl})$, hydrogen peroxide $\left(\mathrm{H}_{2} \mathrm{O}_{2}\right)$ and hydrofluoric acid (HF) [15]. In recent years, our TL laboratory has customised this procedure on the basis of application experience. It was verified that the use of the same reagents in higher concentrations but for a shorter time provides the same results, simultaneously speeding up the method. Moreover, it is not always necessary to proceed with the three reagents in a sequence; depending on the expected composition of the sample and of the burial environment, one single treatment, either with $\mathrm{HCl}$ or with $\mathrm{H}_{2} \mathrm{O}_{2}$, can be chosen. Acetic acid $\left(\mathrm{CH}_{3} \mathrm{COOH}\right)$ in concentrations between $30 \%$ and $10 \% \mathrm{w} / \mathrm{w}$ can also replace hydrogen peroxide in organic matter removal. Considering the shorter reaction time required for this preparation, it can be more convenient when the presence of organic matter is prevalent.

It must also be stressed that each step of the pre-treatment procedure causes the loss of part of the material. This is a critical issue, as only small samples are usually available from artefacts in the cultural heritage domain, particularly if authentication of a precious object is the goal of the whole procedure. To limit these losses, a vacuum system coupled with a $1 \mu \mathrm{m}$ pore-sized paper filter is used to completely retrieve and rinse the powder in one single step. The treated powder is then detached from the filter by a quick transfer in an ultrasonic bath, directly immersing the filter in the next reagent or in acetone if the treatment procedure is accomplished. 
After the chemical treatment, the powder is deposited on the analytical aluminium disks using the fine grain technique described in [26].

\subsection{Final age evaluation}

The age of an object subjected to the complete dating procedure is obtained by calculating the ratio between the palaeodose and the annual dose. Expanding these quantities into their composite terms, the age can be written as

$$
A g e=\frac{E D+S}{k \cdot D_{\alpha}+D_{\beta}+D_{\mathrm{env}}},
$$

where ED is the effective dose measured using $\beta$ irradiation and $S$ is the supralinearity [13], [14]. All contributions to the total annual dose, both internal ( $\alpha$ and $\beta$ ) and external (environmental) to the sample, are set out in the denominator, taking also into account the corrective coefficient $k$ for $\alpha$ dose. To be able to evaluate the annual dose from all the measurements listed above, equation 2 should be made explicit, considering the numerical coefficients extensively described in [13] and [35], which provide a dose rate in $\mu \mathrm{Gy} /$ year and a final age in years, when $W$ is expressed as a fractional number:

$$
\text { Age }=\frac{(E D+S) \cdot 10^{6}}{\frac{k \cdot 1594 \cdot \dot{\alpha}}{1+1.5 \cdot W \cdot F}+\frac{(72.2 \cdot \dot{\alpha})+(782 \cdot K)}{1+1.25 \cdot W \cdot F}+D_{\mathrm{env}}} .
$$

Capital $K$ is the measured potassium content, expressed as percentage by mass. The calculation of age using equation 3 is supported by an ad hoc notebook written in Mathematica software [36]; simply by inserting the measured values and running the program, all the resulting quantities and associated uncertainties are provided in a short time.

\section{CASE STUDY I: DATING OF BRICKS FROM AN EXCAVATION SITE IN TRINO (VC), ITALY}

In 2016, the excavation for the construction of a new gas pipeline in Vercelli province, Piedmont (Italy), revealed the presence of some ancient brick structures. The institution in charge of the rescue of the archaeological site (Soprintendenza Archeologia Belle Arti e Paesaggio delle Province di Biella, Novara, Verbano-Cusio-Ossola e Vercelli) was interested in obtaining TL-dating analyses for bricks from a tomb and from a building found outside the city of Trino, a small town about $60 \mathrm{~km}$ from Torino, at geographical coordinates $45^{\circ} 11^{\prime} 30.5^{\prime \prime} \mathrm{N}-$ $8^{\circ} 16^{\prime} 51.1$ 'E. TL-dating results were especially important, as the site was not particularly rich in moveable findings and was therefore lacking in age reference materials.

\subsection{Structures and in situ sampling}

The first of the two structures chosen for TL analysis was a burial chamber with W-E orientation, built with an outer stone wall and an inner brick one (Figure 2). Inside the tomb, a brick curb was also present. According to the archaeologists, this had been added later to the main construction in order to create a new space for another, smaller corpse. Four bricks were sampled, one from each wall and all from the deepest level of the tomb. In particular, sample T1_C and T1_D were extracted from the main structure, whereas T1_A and T1_B were collected from the inner curb. TLDs were placed in the sampling spots, covered with excavation soil and left in situ for 28 days.

A short distance away from the burial, well-preserved brick flooring with two wooden beams was found (Figure 2). The shape of the bricks and the type of construction suggested to the archaeologists that this building could be much more recent than the tomb. Due to the short time available before the closing of the rescue excavation, only one sample (E1) was retrieved. As it was impossible to leave a dosimeter on site, the environmental dose was obtained, in this case, by means of $\gamma$-spectrometry measurements on both the powdered brick and the surrounding soil.
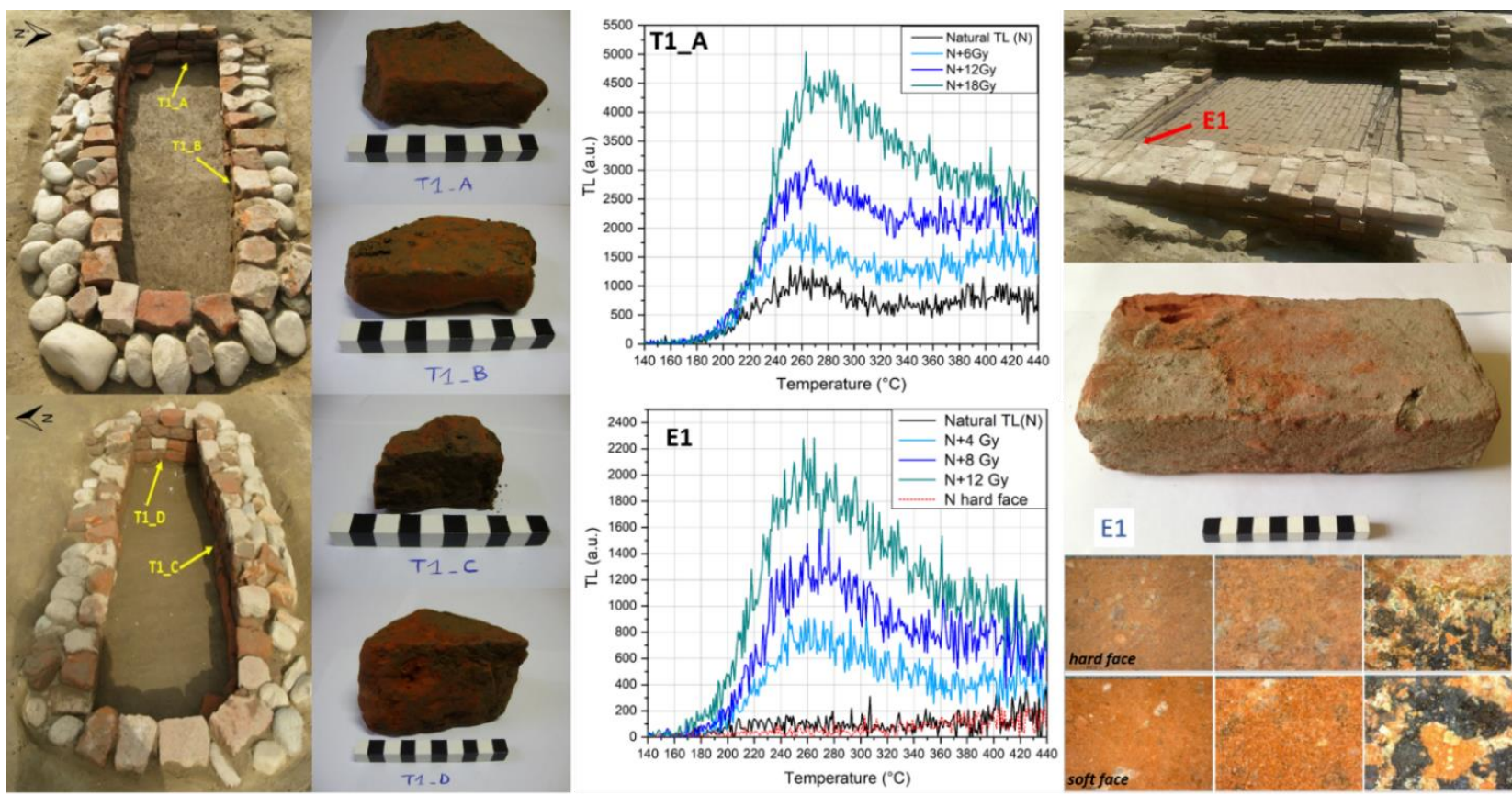

Figure 2. Samples from the Trino excavation site and mean TL glow curves. On the left: tomb T1, its four samples and their original position. On the right: the studied brick from the building (E1) and optical microscope images of its 'hard' face (upper row) and 'soft' face. 
Table 1. Results of TL-dating measurements for samples from Trino. For sample E1, a distinction is reported for results obtained using $\gamma$ spectroscopy on soil (S) and on brick (B).

\begin{tabular}{|c|c|c|c|c|c|}
\hline Sample & T1_A & T1_B & T1_C & T1_D & E1 (soft surface and bulk) \\
\hline \multirow[t]{2}{*}{ Chemical pre-treatment } & $\begin{array}{c}\mathrm{HCl} \\
15 \% \mathrm{w} / \mathrm{w}\end{array}$ & $\begin{array}{c}\mathrm{HCl} \\
15 \% \mathrm{w} / \mathrm{w}\end{array}$ & $\begin{array}{c}\mathrm{HCl} \\
15 \% \mathrm{w} / \mathrm{w}\end{array}$ & $\begin{array}{c}\mathrm{HCl} \\
15 \% \mathrm{w} / \mathrm{w}\end{array}$ & $\mathrm{HCl} 15 \%$ w/w (surface) \\
\hline & & & & & $\mathrm{CH}_{3} \mathrm{COOH} 10 \%$ w/w (bulk) \\
\hline$\#$ ED $\beta$ evaluations & 3 & 3 & 4 & 3 & 3 \\
\hline $\begin{array}{l}\text { Largest T-integration interval from } \\
\text { plateau test }\left(\mathrm{C}^{\circ}\right)\end{array}$ & $320-380$ & $350-390$ & $330-370$ & $350-400$ & $350-380$ \\
\hline$E D \beta(G y)$ & $4.27 \pm 0.28$ & $4.73 \pm 0.11$ & $2.75 \pm 0.08$ & $2.57 \pm 0.19$ & $1.10 \pm 0.18$ \\
\hline Supralinearity & none & none & none & none & none \\
\hline Anomalous fading & none & none & none & none & none \\
\hline Palaeodose (Gy) & $4.27 \pm 0.28$ & $4.73 \pm 0.11$ & $2.75 \pm 0.08$ & $2.57 \pm 0.19$ & $1.10 \pm 0.18$ \\
\hline$\alpha$ counts $\left(\mathrm{ks}^{-1}\right)$ & $16.1 \pm 0.1$ & $13.3 \pm 0.1$ & $13.0 \pm 0.1$ & $12.3 \pm 0.1$ & $11.0 \pm 0.1$ \\
\hline W (\%) & $16.65 \pm 0.01$ & $13.65 \pm 0.01$ & $11.48 \pm 0.01$ & $15.29 \pm 0.01$ & $13.52 \pm 0.01$ \\
\hline $\mathrm{K}(\% \mathrm{w} / \mathrm{w})$ & $1.26 \pm 0.08$ & $1.16 \pm 0.08$ & $1.30 \pm 0.09$ & $1.27 \pm 0.09$ & $1.19 \pm 0.08$ \\
\hline $\mathrm{ED} \alpha(\mathrm{Gy})$ & $233 \pm 35$ & $115 \pm 23$ & $66 \pm 3$ & $37 \pm 5$ & $23 \pm 5$ \\
\hline$k$ coefficient & $0.015 \pm 0.003$ & $0.034 \pm 0.007$ & $0.035 \pm 0.002$ & $0.058 \pm 0.009$ & $0.040 \pm 0.010$ \\
\hline Environmental dose ( $\mu \mathrm{Gy} /$ year) & $1290 \pm 40$ & $1460 \pm 60$ & $1430 \pm 190$ & $1210 \pm 250$ & $\begin{array}{l}S 670 \pm 90 \\
B 1040 \pm 100\end{array}$ \\
\hline Annual dose ( $\mu \mathrm{Gy} /$ year) & $3470 \pm 230$ & $3740 \pm 240$ & $3840 \pm 270$ & $3820 \pm 350$ & $\begin{array}{l}S 2800 \pm 240 \\
B 3160 \pm 250\end{array}$ \\
\hline Age (AD) & $790 \pm 110$ & $750 \pm 80$ & $1300 \pm 50$ & $1340 \pm 70$ & $\begin{array}{l}S 1620 \pm 60 \\
B 1670 \pm 50\end{array}$ \\
\hline
\end{tabular}

\subsection{TL-dating procedures}

For each brick from the grave, at least three values of effective dose (ED) were calculated using the additive dose method [13] with $\beta$ irradiations (Figure 3); the effective dose is exactly equal to the palaeodose if supralinearity is absent. The collected powder (about $1 \mathrm{~g}$ per sampling by drilling) was treated only with $\mathrm{HCl} 15 \% \mathrm{w} / \mathrm{w}$ for 45 minutes, but no evidence of the formation of gaseous carbon dioxide was observed.

The brick from the building presented a peculiar hardness on one of the larger faces, whereas the specular face had a soft ceramic body and was easy to sample with the drill. The comparison of microscopical observations did not highlight differences beyond a more intense reddish hue of the soft part; however, the TL natural signals were quite different, as the one from the hard side seemed to be lower than the one from the soft side at temperatures below $300{ }^{\circ} \mathrm{C}$ (see Figure 2). Powder from the bulk was also analysed, and the TL response was compatible with the soft side. It could be assumed that this brick was subjected to an inhomogeneous kiln firing or that a high temperature blaze had reached it. Based on this hypothesis, only results from the soft face and the bulk were considered for statistical purposes in the effective dose determination, although the chemical treatments were different for the two parts of the brick. Powder from the surface was treated for 45 minutes with $\mathrm{HCl} 15 \% \mathrm{w} / \mathrm{w}$; however, in the bulk, the organic component was high enough to alter the TL natural signal, so a 60 -minute treatment with $\mathrm{CH}_{3} \mathrm{COOH} 10 \% \mathrm{w} / \mathrm{w}$ was preferred.

In addition, for all the samples, about $1 \mathrm{~g}$ per brick was subjected to $\alpha$ spectroscopy. The absence of supralinearity was verified using the regenerative method [13], anomalous fading was checked and $\mathrm{K}$ quantifications with ICP-OES were performed. Finally, the effective dose via $\alpha$ irradiation was also obtained in order to calculate the $k$ coefficient. All the values resulting from the TL-dating procedure can be found in Table 1. These are directly measured (ED $\beta$, supralinearity, anomalous fading, $\alpha$ counts, $\mathrm{W} \%, \mathrm{~K} \% \mathrm{w} / \mathrm{w}, \mathrm{ED} \alpha$, environmental dose) or derived via calculation using the same measured values (palaeodose, $k$ coefficient, annual dose and, finally, the age).

\subsection{TL-dating results}

The age determination for samples coming from tomb T1 led to a very interesting result: bricks T1_A and T1_B from the inner curb were dated to the end of the eighth century AD $(790 \pm 110$ $\mathrm{AD}$ and $750 \pm 80 \mathrm{AD}$, respectively) but the other two samples to the fourteenth century AD (1300 \pm 50 AD for T1_C and 1340 \pm 70 AD for T1_D). In such a case, TL dating assigns the burial as contemporary or subsequent to the more recent component; hence, reused material had been employed for building the curb. It should be noted that the medieval bricks could have been reused as well; a comparison with radiocarbon dating on the skeletons could then be crucial but, unfortunately, the bones and teeth had deteriorated too much as a result of the highly acidic soil. The case of this tomb highlights how important the in-situ sampling phase can be in results interpretation. If only bricks near T1_A and T1_B had been collected, they would not have been representative of the real age of the tomb and would have led to an inaccurate attribution.

Due to the impossibility of using an environmental dosimeter, the age determination for the brick from the floor led to two values, depending on whether the annual dose was determined by means of $\gamma$-spectroscopy measurements on the brick itself or on the surrounding soil: $1670 \pm 50 \mathrm{AD}$ using the brick and 1620 $\pm 60 \mathrm{AD}$ using the soil. The two calculated ages are compatible and confirm in both cases the archaeological hypothesis of a more recent construction. This is additionally supported by the results of radiocarbon-dating analysis performed at the INFNLABEC laboratory (Florence) on one of the wooden beams. The measured radiocarbon age $(125 \pm 25$ years $\mathrm{BP})$ classifies the sample as modern, meaning that its calibrated calendar age falls between approximately $1650 \mathrm{AD}$ and $1955 \mathrm{AD}$. It is worth noting that, in this case, TL led to a more precise date in respect 


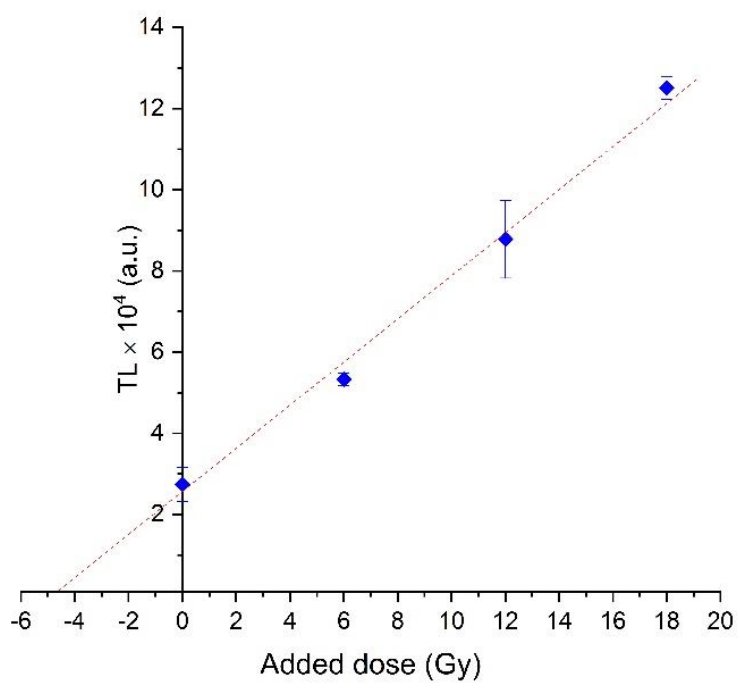

Figure 3. Resulting fit for the additive method applied to one measured set of sample T1_A. Corresponding mean glow curves are reported in Figure 2; the temperature interval for signal integration was $340-380{ }^{\circ} \mathrm{C}$. The intercept on the $x$-axis, i.e. the effective dose (ED), is $4.75 \pm 0.66 \mathrm{~Gy}$.

of radiocarbon. However, although the flooring appeared very homogeneous in material constitution, the analysis of only one brick from the building cannot represent the whole structure.

\section{CASE STUDY II: AUTHENTICATION OF PRE-COLUMBIAN POTTERY}

In 2019, a ceramic artefact from the Dominican Republic was studied to be authenticated. The analysed object (Figure 4) is a symmetrical shaped bottle about $60 \mathrm{~cm}$ high, and it was attributed to the pre-Columbian population inhabiting the island before the European conquest in the late fifteenth century. Clay pottery was introduced to the Caribbean islands, from the Lesser Antilles to Puerto Rico, by people from the 'early ceramic age' around $500 \mathrm{BC}$. In Hispaniola, for reasons still unknown, ceramics production was introduced about one millennium later, although older ceramics have been found resulting from interisland transport, as evidenced by the exchange of heirlooms [37], [38]. The assignation of this artefact to the pre-Columbian period and related populations could enrich the knowledge and studies on stylistics and trade routes.

\subsection{Sampling and analysis}

The authentication procedure can be described as a test to verify if measurable TL parameters, in particular ED, are compatible with values expected for an artefact belonging to the period suggested by archaeologists on the basis of stylistic features [4], [39]-[41]. Usually, due to the value of the objects to be authenticated, only a small quantity of powder can be sampled, weighing some few hundreds of milligrams. The scarce availability of material to be analysed prevents the measuring of all the parameters described above for TL dating. Moreover, authentication is usually requested only for decontextualised objects, i.e. when the exact burial spot or the conservation place is unknown. In these cases, it is not possible to retrieve the specific environmental dose, and the whole set of values for one or more possible provenance areas must be considered. If necessary, data can be partially obtained from the scientific literature, although, in many cases, these data are scarce or absent for a specific typology of object or geographical area.
In the case under investigation, it was possible to collect $480 \mathrm{mg}$ of powder from the base of the artefact. The whole amount was first used to measure the $\alpha$ activity, which is sufficient in many cases, together with the ED measurement, to address the authentication issues, and is, nonetheless, useful additional information to complement the literature. The same powder, unmodified in any way, was then used to determine the effective dose via the additive method using $9 \mathrm{~Gy}$ and $18 \mathrm{~Gy} \beta$ doses. Usually, pre-treatments in authentication are reduced to a minimum in order to preserve the small quantity of powder available. No chemical pre-treatment was performed in this case due to the suitable TL response of the material.

\subsection{Authentication results}

The glow curves obtained with the additive method are reported in Figure 4, and the corresponding effective dose resulted in $8.5 \pm 1.0 \mathrm{~Gy}$. Anomalous fading was negligible.

The annual dose for similar objects from Hispaniola was not found in the scarce literature, but by using the maximum spread of the values indicated for neighbouring areas [37], [38], [42], [43], a reasonable interval of 2.2-6.2 $\mathrm{mGy} /$ year could be considered. The value obtained for the effective dose leads to a minimum age of about 1,000 years, when the minimum ED at $2 \sigma$ and the maximum annual dose values are considered.

It is worth noting that the measured $\dot{\alpha}$ rate from the $\alpha$ activity can also be used to roughly estimate the minimum age of the artefact. In this case, the $\dot{\alpha}$ rate was $9.6 \pm 0.1$ counts $/ \mathrm{ks}$, and the subsequently calculated $\alpha$ contribution to the annual dose was $1.4 \pm 0.7 \mathrm{mGy} /$ year, considering a wide range for $k(k=0.10 \pm$ $0.05)$ and moisture $(F=0.8 \pm 0.2$ and $W=0.1 \pm 0.1)$ values reported in the general literature [13]. Moreover, by setting the potassium content arbitrarily, albeit reasonably, to $K=2 \pm 2 \%$ and the cosmic ray contribution to $160 \pm 160 \mu \mathrm{Gy} /$ year [13], [38], [42]-[44], a total annual dose interval of 0.4-9.2 mGy/year was obtained for the studied sample, taking the $\pm 2 \sigma$ range into account. This result is in accordance with the values found in the literature for the neighbouring area. The annual dose range can be reduced by also measuring the $k$ value and potassium content (if the amount of powder is sufficient, as around $40 \mathrm{mg}$ is needed for ICP-OES analysis). In this case, it was not necessary since the results obtained by means of $\alpha$ counting were adequate to address the authentication issue. In fact, considering a value of ED-2 $\sigma$ and the maximum annual dose in the new range, the minimum age found was about 700 years.

In both cases, by means of $\alpha$ counting or referring to the literature, the results led to a compatibility with the TL measurements of an artefact that was last fired in a period prior to the arrival of Europeans in the Americas. It is not possible to identify a more precise timeframe attribution because, in terms
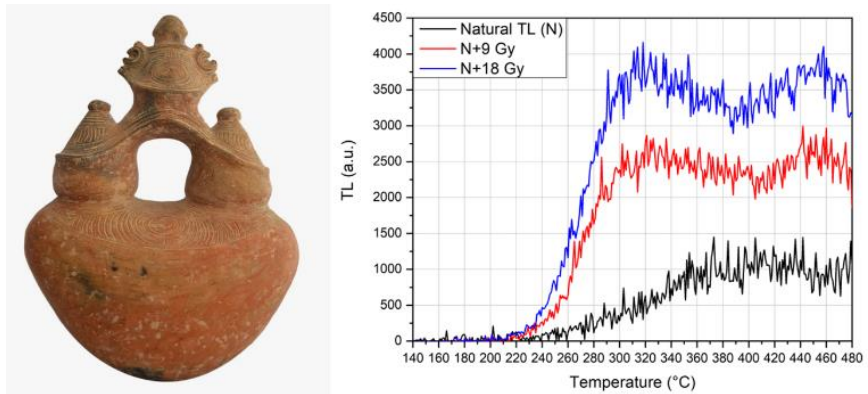

Figure 4. On the left: the object intended for authentication with thermoluminescence. On the right: mean glow curves from the additive method. 
of the minimum annual dose in the range, all the sub-periods in the early Caribbean ceramic age are possible. It must be stressed that authentication does not provide an age (expressed as date \pm error) but only allows the confirmation or denial of the hypothesis of the experts attributing the artefact to a specific historical period.

\section{CONCLUSIONS}

Improvements made in the thermoluminescence dating laboratory at the University of Torino have led to faster and partially automated methods, but they still remain tailored to the specific artefact under investigation. The approach to dating starts with a representative sampling in situ and a flexible chemical pre-treatment, if needed. The new irradiation systems allow more data to be collected in the same amount of operating time, enlarging the dataset employed for statistical treatment.

Analyses of brick samples from the rescue excavation site in Trino led to a dating result with less than $10 \%$ of sigma for the tomb and $15 \%$ of sigma for the brick flooring. The tomb appears to be contemporary or subsequent to the fourteenth century, and the reuse of building material is evident for part of the construction. For the adjacent flooring, the archaeological hypothesis of a more recent construction was proved, it being dated at least to the seventeenth century AD. This result is in accordance with the radiocarbon dating of a structural wooden beam. Moreover, this case study verified that, when on-site dosimetry is not available, it is possible, in some cases, to achieve good results considering as a first approximation the annual dose obtained by $\gamma$-spectrometry measurements on both the powdered sample and the surrounding soil. Dating results aided the archaeologists to define the habitation period of Trino's surroundings.

The instrumentation is also extremely useful for authentication purposes where the effective dose is generally compared to bibliographic values in order to verify artefact compatibility with the attributed period. In addition, the possibility of measuring $\alpha$ activity allows a rough calculation of the annual dose. This can be very important when relevant literature is scarce, as in the case of the Caribbean artefact presented here, which was confirmed to be compatible with preColumbian production.

TL measurements in the cultural heritage field can produce a considerable amount of data that can be combined with literature sources and subjected to an extensive statistical analysis, providing additional information for archaeological issues.

\section{ACKNOWLEDGEMENTS}

The authors wish to warmly thank CHNet, the INFN network of laboratories working in the cultural heritage field, for supporting this research in terms of instrumentation, competencies and grants and, in particular, the INFN-LABEC laboratory in Florence for performing radiocarbon dating analysis. Thanks are due to Prof. Ettore Vittone for his support for the activities. The authors are grateful to Compagnia di San Paolo for their financial support, Prof. Roberto Cirio for the availability of the $\gamma$-spectrometry apparatus and all the research fellows, graduate and undergraduate students that have contributed in some way to the laboratory's development over the years.

\section{REFERENCES}

[1] A. L. Watchman, C. R. Twidale, Relative and 'absolute' dating of land surfaces, Earth-Sci. Rev. 58 (2002) pp. 1-49. DOI: $10.1016 /$ S0012-8252(01)00080-0

[2] J. Sanjurjo-Sánchez, Dating historical buildings: an update on the possibilities of absolute dating methods, Int. J. Archit. Herit. 10 (2016) pp. 620-635. DOI: $10.1080 / 15583058.2015 .1055384$

[3] B. Desachy, From observed successions to quantified time: formalizing the basic steps of chronological reasoning, Acta IMEKO 5 (2016) 2, pp. 4-13.

DOI: $\underline{10.21014 / \text { acta imeko.v5i2.353 }}$

[4] D. W. Zimmerman, M. P. Yuhas, P. Meyers, Thermoluminescence authenticity measurements on core material from the Bronze Horse of the New York Metropolitan Museum of Art, Archaeometry 16 (1974) pp. 19-30. DOI: $10.1111 /$ j.1475-4754.1974.tb01089.x

[5] S. D. Costello, P. Klausmeyer, A re-united pair: the conservation, technical study and ethical decisions involved in exhibiting two terracotta orante statues from Canosa, Stud. Conserv. 59 (2014) pp. 377-390. DOI: $10.1179 / 2047058413$ Y.0000000103

[6] A. Lo Giudice, A. Re, D. Angelici, S. Calusi, N. Gelli, L. Giuntini, M. Massi, G. Pratesi., In-air broad beam ionoluminescence microscopy as a tool for rocks and stone artworks characterisation, Anal. Bioanal. Chem. 404 (2012) pp. 277-281.

DOI: $10.1179 / 2047058413$ Y.0000000103

[7] A. Re, D. Angelici, A. Lo Giudice, J. Corsi, S. Allegretti, A. F. Biondi, G. Gariani, S. Calusi, N. Gelli, L. Giuntini, M. Massi, F. Taccetti, L. La Torre, V. Rigato, G. Pratesi, Ion beam analysis for the provenance attribution of lapis lazuli used in glyptic art: the case of the "Collezione Medicea", Nucl. Instrum. Meth. B 348 (2015) pp. 278-284.

DOI: $10.1016 /$ i.nimb.2014.11.060

[8] A. Lo Giudice, A. Re, D. Angelici, J. Corsi, G. Gariani, M. Zangirolami, E. Ziraldo, Ion microbeam analysis in cultural heritage: application to lapis lazuli and ancient coins, Acta IMEKO 6 (2017) 3, pp. 76-81.

DOI: $\underline{10.21014 / \text { acta imeko.v6i3.465 }}$

[9] A. Lo Giudice, D. Angelici, A. Re, G. Gariani, A. Borghi, S. Calusi, L. Giuntini, M. Massi, L. Castelli, F. Taccetti, T. Calligaro, C. Pacheco, Q. Lemasson, L. Pichon, B. Moignard, G. Pratesi, M. C. Guidotti, Protocol for lapis lazuli provenance determination: evidence for an Afghan origin of the stones used for ancient carved artefacts kept at the Egyptian Museum of Florence (Italy), Archaeol. Anthrop. Sci. 9 (2017) pp. 637-651. DOI: $10.1007 / \mathrm{s} 12520-016-0430-0$

[10] A. Re, M. Zangirolami, D. Angelici, A. Borghi, E. Costa, R. Giustetto, L. M. Gallo, L. Castelli, A. Mazzinghi, C. Ruberto, F. Taccetti, A. Lo Giudice, Towards a portable X-Ray luminescence instrument for applications in the cultural heritage field, Eur. Phys. J. Plus 133 (2018) pp. 362-368.

DOI: $10.1140 /$ epjp/i2018-12222-8

[11] E. Tema, F. Fantino, E. Ferrara, S. Allegretti, A. Lo Giudice, A. Re, F. Barello, S. Vella, L. Cirillo, M. Gulmini, Archaeological, archaeomagnetic and thermoluminescence study of a baked clay kiln excavated at Chieri, Northern Italy: contribution to the rescue of our cultural heritage, Ann. Geophys-Italy 57 (2014) G0548:9p. DOI: $10.4401 / \mathrm{ag}-6611$

[12] E. Tema, F. Fantino, E. Ferrara, A. Lo Giudice, J. Morales, A. Goguitchaichvili, P. Camps, F. Barello, M. Gulmini, Combined archaeomagnetic and thermoluminescence study of a brick kiln excavated at Fontanetto Po (Vercelli, Northern Italy), J. Archaeol. Sci. 40 (2013) pp. 2025-2035. DOI: $10.1016 /$ j.jas.2012.12.011

[13] M. J. Aitken, Thermoluminescence Dating, Academic Press, London, 1985, ISBN 0120463814 
[14] A. G. Wintle, Fifty years of luminescence dating, Archaeometry 50 (2008) pp. 276-312. DOI: $10.1111 / \mathrm{i} .1475-4754.2008 .00392 . \mathrm{x}$

[15] E. Vieillevigne, P. Guibert, F. Bechtel, Luminescence chronology of the medieval citadel of Termez, Uzbekistan: TL dating of brick masonries, J. Archaeol. Sci. 34 (2007) pp. 1402-1416. DOI: $10.1016 /$ i.jas.2006.10.030

[16] S. O. Troja, A. Cro, A. M. Gueli, V. L. Rosa, P. Mazzoleni, A. Pezzino, M. Romeo, Characterization and thermoluminescence dating of prehistoric pottery sherds from Milena, Archaeometry 38 (1996) pp. 113-128. DOI: $10.1111 /$ i.1475-4754.1996.tb00765.x

[17] L. Carobene, R. Cirrincione, R. De Rosa, A. M. Gueli, S. Marino, S. O. Troja, Thermal (TL) and optical stimulated luminescence (OSL) techniques for dating Quaternary colluvial volcaniclastic sediments: an example from the Crati Basin (Northern Calabria), Quatern. Int. 148 (2006) pp. 149-164. DOI: $10.1016 /$ i.quaint.2005.11.010

[18] A. M. Gueli, G. Stella, S. O. Troja, G. Burrafato, G. Margani, A. R. Zuccarello, Absolute dating of the Cuba of Santa Domenica (Messina, Italy), Nuovo Cim. B 124 (2009) pp. 885-891.

DOI: $10.1393 / \mathrm{ncb} / \mathrm{i} 2010-10818-2$

[19] F. Preusser, M. Chithambo, T. Gotte, M. Martini, K. Ramseyer, E. J. Sendezera, G.J. Susino, A. G. Wintle, Quartz as a natural luminescence dosimeter, Earth-Sci. Rev. 97 (2009) pp. 184-214. DOI: $\underline{10.1016 / \text { i.earscirev.2009.09.006 }}$

[20] A. Cardinale, L. Frittelli, G. Lembo, F. Gera, O. Ilari, Studies on the natural background radiation in Italy, Health Phys. 20 (1971) pp. 285-296. DOI: $10.1097 / 00004032-197103000-00006$

[21] L. Guidotti, F. Carini, R. Rossi, M. Gatti, R. M. Cenci, G. M. Beone, Gamma-spectrometric measurement of radioactivity in agricultural soils of the Lombardia region, northern Italy, J. Environ. Radioactiv. 142 (2015) pp. 36-44.

DOI: $10.1016 /$ j.jenvrad.2015.01.010

[22] J. A. Plant, S. Reeder, R. Salminen, D. B. Smith, T. Tarvainen, B. De Vivo, M. G. Petterson, The distribution of uranium over Europe: geological and environmental significance, Applied Earth Science 112 (2003) pp. 221-238. DOI: $10.1179 / 037174503225003152$

[23] D. W. Zimmerman, J. Huxtable, Thermoluminescent dating of upper Palaeolithic fired clay from Dolní Věstonice, Archaeometry 13 (1971) pp. 53-57. DOI: $10.1111 / \mathrm{i} .1475-4754.1971 . t b 00029 . x$

[24] A. G. Wintle, Anomalous fading of thermoluminescence in mineral samples, Nature 245 (1973) pp.143-144. DOI: $10.1038 / 245143 \mathrm{a} 0$

[25] M. Martini, E. Sibilia, Radiation in archaeometry: archaeological dating, Radiat. Phys. Chem. 61 (2001) pp. 241-246. DOI: $\underline{10.1016 / \mathrm{S} 0969-806 \mathrm{X}(01) 00247-\mathrm{X}}$

[26] D. Zimmerman, Thermoluminescence dating using fine grains from pottery, Archaeometry 13 (1971) pp. 29-52. DOI: $10.1111 / j .1475-4754.1971 . t b 00028 . x$

[27] M. Martini, E. Sibilia, T. Calderon, F. Di Renzo, Spurious thermoluminescence in archaeological ceramics: a study of affecting factors, Int. J. Radiat. Appl. Instrum. Part D 14 (1988) pp. 339-342. DOI: $10.1016 / 1359-0189(88) 90086-6$

[28] P. Guibert, I. K. Bailiff, S. Blain, A. M. Gueli, M. Martini, E. Sibilia, G. Stella, S. O. Troja, Luminescence dating of architectural ceramics from an early medieval abbey: the St. Philbert intercomparison (Loire Atlantique, France), Radiat. Meas. 44 (2009) pp. 488-493.

DOI: $10.1016 /$ i.radmeas.2009.06.006
[29] D. W. Zimmerman, Relative thermoluminescence effects of alpha- and beta-radiation, Radiation Effects 14 (1972) pp. 81-92. DOI: $10.1080 / 00337577208230476$

[30] Los Alamos National Laboratory, MCNP: A General Monte Carlo N-Particle Transport Code. Online [Accessed 6 April 2020] https://mcnp.lanl.gov/

[31] M. J. Kim, S. Y. Kim, J. I. Lee, J. L. Kim, I. Chang, D. G. Hong, Environmental gamma-ray dose rate measurement by using ultrahigh sensitive LiF:Mg,Cu,Si TLD, Radiat. Meas. 56 (2013) pp. 248251.

DOI: $10.1016 /$ i.radmeas.2013.02.011

[32] R. L. Meakins, B. L. Dickson, J. C. Kelly, Gamma-ray analysis of $\mathrm{K}, \mathrm{U}$ and $\mathrm{Th}$ for dose-rate estimation in thermoluminescent dating, Archaeometry 21 (1979) pp. 79-86. DOI: $10.1111 / \mathrm{i} .1475-4754.1979 . t b 00243 . \mathrm{x}$

[33] M. Losana, M. Magnoni, F. Righino, Comparison of different methods for the assessment of the environmental gamma dose, Radiat. Prot. Dosim. 97 (2001) pp. 333-336. DOI: 10.1093 /oxfordjournals.rpd.a006683

[34] T. S. Park, W. J. Jeon, Measurement of radioactive samples in Marinelli beakers by gamma-ray spectrometry, J. Radioan. Nucl. Ch. Ar. 193 (1995) pp. 133-144. DOI: $10.1007 / \mathrm{BF} 02041927$

[35] G. Adamiec, M. J. Aitken, Dose-rate conversion factors: update, Ancient TL 16 (1998) pp. 37-50.

[36] Wolfram Mathematica, The world's definitive system for modern technical computing. Online [Accessed 6 April 2020] https://www.wolfram.com/mathematica/

[37] W. F. Keegan, West Indian archaeology. 3. Ceramic Age, J Archaeol. Res. 8 (2000) pp. 135-167. DOI: 10.1023/A:1009403127753

[38] S. M. Fitzpatrick, Q. Kaye, J. Feathers, J. A. Pavia, K. M. Marsaglia, Evidence for inter-island transport of heirlooms: luminescence dating and petrographic analysis of ceramic inhaling bowls from Carriacou, West Indies, J. Archaeol. Sci. 36 (2009) pp. 506-606. DOI: $10.1016 /$ i.jas.2008.08.007

[39] M. J. Aitken, P. R. S. Moorey, P.J. Ucko, The authenticity of vessels and figurines in the Hacilar style, Archeaometry 13 (1971) pp. 89-141. DOI: $10.1111 / \mathrm{j} .1475-4754.1972 . t b 00059 . x$

[40] S. J. Fleming, D. Stoneham, Thermoluminescent authenticity study and dating of Renaissance terracottas, Archeaeometry 15 (1973) pp. 239-247.

DOI: $10.1111 /$ i.1475-4754.1973.tb00094.x

[41] P. L. Leung, Q. Tang, M. Li, C. Zhang, The preliminary application of OSL in comparison with TL for authentication of ancient Chinese bricks, Radiat. Meas. 40 (2005) pp. 1-4.

DOI: $10.1016 /$ i.radmeas.2004.05.012

[42] P. Gonzales, J. Azorin, P. Schaaf, A. Ramirez, Assessing the potential of thermoluminescence dating of pre-conquest ceramics from Calixtilahuaca, Mexico, Radiat. Prot. Dosim. 84 (1999) pp. 483-487.

DOI: 10.1093 /oxfordjournals.rpd.a032782

[43] H. Chung, P. Gonzales, A. Ramirez, P. Shaaf, I. Lee, Rethinking about chronology of Chichen Itza by thermoluminescence dating of volcanic glass, Mediterr. Archaeol. Ar. 10 (2010) pp. 115-120.

[44] M. J. Aiuvalasit, J. A. Neely, M. D. Bateman, New radiometric dating of water management features at the prehistoric Purrón Dam Complex, Tehuacán Valley, Puebla, México, J. Archaeol. Sci. 37 (2010) pp. 1207-1213.

DOI: $\underline{10.1016 / \text { i.jas.2009.12.019 }}$ 